\title{
Clinical outcome of weaning in mechanically ventilated patients with chronic obstructive pulmonary disease Suzan Salama Sayed ${ }^{a}$, Khalid Hussein Ahmed $^{a}$, Sayed Abdelsabour Kinawy ${ }^{b}$, Islam Galal Sayed ${ }^{\mathrm{b}}$
}

\begin{abstract}
Background Chronic obstructive pulmonary disease (COPD) represents a significant reason for mortality and morbidity worldwide that induces a high socioeconomic burden, with exacerbations necessitating mechanical ventilation representing a major aspect of illness management. Many patients with COPD frequently presented with troubles in the liberation from mechanical ventilation. The aim of the current study was to verify the validity of the weaning categorization that is classified according to the difficulty and length of the weaning procedure in mechanically ventilated patients with COPD and its effect on the different clinical and mortality outcome variables.
\end{abstract}

Patients and methods A total of 102 patients with COPD who achieved the weaning criteria were classified according to the length and difficulty of weaning procedure into simple weaning group ( $n=60,58.8 \%)$ and nonsimple weaning group (which include difficult and prolonged weaning categories) $(n=42,42.2 \%)$. The outcome measures are the length of mechanical ventilation, the duration of ICU stay, and lastly the mortality rate.

Results Regarding baseline data recorded at admission, no significant difference between both weaning groups was found apart from Acute Physiology and Chronic Health

\section{Introduction}

Morbidity and mortality owing to chronic obstructive pulmonary disease (COPD) represents a worldwide pandemic. Severe COPD exacerbations may require mechanical ventilation, which is lifesaving [1]. Once mechanical ventilation is initiated, planning for weaning off should be started. Timing of weaning is crucial to avoid many complications. Weaning off mechanically ventilated patients with COPD is considered a major challenge in critical care practice. Weaning was categorized according to the length and difficulty of the weaning procedure into three categories (simple, difficult, and prolonged weaning categories), according to the latest recommendations [2].

Weaning should be performed early as soon as possible. It is important to recognize those patients at the time of admission who are likely to have poor outcome, so that such patients can be monitored closely and managed aggressively [3].

A topic of constant research for over many years is the difficulty to predict the weaning outcome in patients with COPD undergoing mechanical ventilation [2].

\begin{abstract}
Evaluation score II. The nonsimple weaning group had considerably higher duration of invasive mechanical ventilation, length of ICU stays, and lastly the mortality rate, in comparison with the simple weaning group.
\end{abstract}

Conclusion Weaning categorization according to the length and the difficulty of the weaning procedure may be used as a suitable predictor of outcome in severe COPD exacerbation with the requirement for invasive mechanical ventilation.

Egypt J Bronchol 2019 13:484-488

(C) 2019 Egyptian Journal of Bronchology

Egyptian Journal of Bronchology 2019 13:484-488

Keywords: chronic obstructive pulmonary disease, mechanical ventilation, simple weaning, weaning

aProfessor of Chest Diseases and TB, Faculty of Medicine, Assiut University ${ }^{\mathrm{b}}$ Lecturer of Chest Diseases and TB, Faculty of Medicine, Aswan University, Egypt

Correspondence to Islam Galal Sayed, MD in Chest Diseases and Tuberculosis, Lecturer of Chest Diseases and TB, Faculty of Medicine, Aswan University, 17111, Egypt. Tel: 01116681549; e-mail: islamgalal76@yahoo.com

Received: 21 January 2019 Revised: 4 March 2019 Accepted: 19 May 2019 Published: 25 October 2019

This study aimed to verify the validity of the weaning classification and its effect on the outcome in mechanically ventilated patients with COPD.

\section{Patients and methods}

\section{Study design and setting}

This is an observational study conducted in a RICU, during the period from October 2017 to April 2018.

\section{Study population}

A total of 183 patients with COPD requiring invasive mechanical ventilation were admitted in our RICU [ventilation was performed with the Puritan-Bennett 840 ventilator (Nellcor Puritan-Bennett 840 ventilator, Florida, USA)]. Of them, 81 patients did not start weaning either because of death in 66 patients or unplanned extubation in 15 patients. The remaining

This is an open access journal, and articles are distributed under the terms of the Creative Commons Attribution-NonCommercial-ShareAlike 4.0 License, which allows others to remix, tweak, and build upon the work non-commercially, as long as appropriate credit is given and the new creations are licensed under the identical terms. 


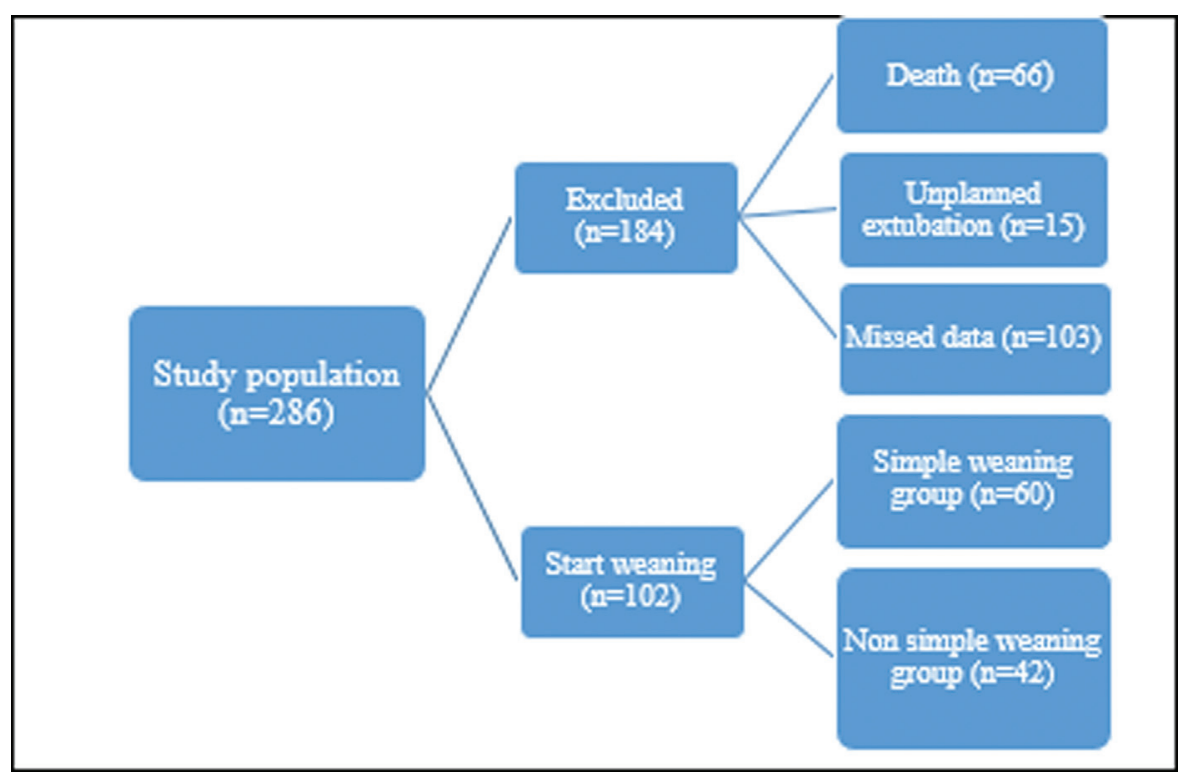

Scheme of the result analysis. The flow chart shows that the study includes 183 patients; however, 81 patients were excluded as 66 patients died before the start of weaning and 15 patients had unplanned extubation. Therefore, the included 102 patients were classified into simple weaning group (60 patients) and nonsimple weaning group (42 patients).

102 patients met the weaning criteria and start weaning, as shown in Fig. 1.

\section{Inclusion criteria}

The study included all patients with COPD requiring invasive mechanical ventilation with the following criteria: respiratory rate more than or equal to 35 breath/min, use of accessory muscles of respiration, disturbed conscious level, respiratory acidosis, and $\mathrm{PaO}_{2} / \mathrm{FiO}_{2}$ less than 200 .

\section{Exclusion criteria}

The exclusion criteria include age less than 18 years, patients with central nervous system disorders unrelated to hypercapnic encephalopathy or hypoxemia, patients with postarrest encephalopathy, and patient with previous tracheostomy.

\section{Study classification}

Patients were classified according to the duration and difficulty of weaning procedure into two groups: simple weaning group included 60 patients who tolerated the first trial of spontaneous breathing, and nonsimple weaning group (including difficult and prolonged weaning category) included 42 patients, of which the difficult weaning category included 37 patients who failed first spontaneous breathing trial (SBT) but succeeded on second or third trial within 7 days, and the prolonged weaning category included five patients who did not tolerate at least three weaning trials or when weaning duration exceeded 7 days from the first trial of weaning.
The following data were recorded:

(1) Demographic data including age, sex, smoking, and BMI.

(2) Arterial blood gases.

(3) Full laboratory assessment.

(4) Hemodynamic data, including mean arterial blood pressure, calculated as diastolic pressure $+1 / 3$ pulse pressure, respiratory rate (RR), heart rate, and temperature.

(5) Acute Physiology and Chronic Health Evaluation (APACHE) II score was measured on the day of ICU admission. APACHE II score consists of 12 variables including, vital signs (heart rate, mean arterial blood pressure, RR, temperature, and Glasgow coma score), variables derived from routine venous blood tests (hematocrit, white blood cell count, serum potassium, serum sodium, and serum creatinine), and two variables derived from arterial blood gas tests (serum $\mathrm{pH}$ and $\mathrm{PaO}_{2}$ ).

(6) Ventilatory data were recorded at admission and after half hour of SBT, including spontaneous tidal volume, RR, minute ventilation, peak pressure, plateau pressure, and static compliance. Values were displayed on the ventilator and we used the average of three breaths. In addition, weaning indices were recorded including rapid shallow breathing index (RSBI) obtained by dividing spontaneous RR by exhaled tidal volume (1) and the new integrative weaning index (IWI) calculated as (Cst, $\left.\mathrm{rs} \times \mathrm{SaO}_{2} / \mathrm{RSBI}\right)$, in which Cst, rs is static compliance and $\mathrm{SaO}_{2}$ is arterial oxygen saturation. 
All patients who fulfilled the subsequent weaning criteria underwent SBT, which comprised the respiratory criteria, including sufficient inspiratory effort, $\mathrm{PaO}_{2}$ more than $60 \mathrm{mmHg}$ or $\mathrm{SaO}_{2}$ more than or equal to $90 \%$ or more with $\mathrm{FiO}_{2}$ less than or equal to 0.4 , and normal or baseline $\mathrm{PaCO}_{2}$, and cardiovascular criteria, involving heart rate less than or equal 140 beats/min, absence of myocardial ischemia and within normal mean arterial blood pressure without the necessity for the use of vasopressors, patient is arousable or has Glasgow coma score more than or equal to 13 , and there were no electrolyte disturbances.

\section{Ethical consideration}

The study was agreed by the Institutional Ethics Committee Faculty of Medicine. Moreover, a written consent was given by the surrogate decision maker.

\section{Statistical analysis}

Statistical analysis was done by SPSS, version 21 (IBM Inc., Armonk, New York, USA). Nonparametric tests were used in the current study.

\section{Results}

Demographic data and patient characteristics at admission of both groups of weaning are summarized in Table 1. There was a major significant variation between both groups regarding the APACHE II score, whereas there was no significant difference regarding the other parameters.

Regarding the ventilator parameters at the end of the first SBT, the simple weaning group illustrated highly significant higher values for exhaled tidal volume and static compliance and lower values for RR and exhaled minute ventilation, whereas regarding peak pressure, plateau pressure, and auto-positive end expiratory pressure, no significant differences between both groups were observed (Table 2).

Table 2 Ventilator parameters at the end of the first spontaneous breathing trial

\begin{tabular}{lccc}
\hline & $\begin{array}{c}\text { Simple } \\
\text { weaning } \\
(N=60)\end{array}$ & $\begin{array}{c}\text { Nonsimple } \\
\text { weaning }(N=42)\end{array}$ & $\begin{array}{c}P \\
\text { value }\end{array}$ \\
\hline $\begin{array}{l}\text { Exhaled tidal } \\
\text { volume }(\mathrm{ml})\end{array}$ & $360 \pm 80$ & $280 \pm 90$ & $0.000^{*}$ \\
$\mathrm{RR}($ breath/min) & $23.92 \pm 4.60$ & $32.98 \pm 5.62$ & $0.000^{*}$ \\
$\mathrm{P}$ peak $\left(\mathrm{cmH}_{2} \mathrm{O}\right)$ & $21.58 \pm 3.29$ & $21.02 \pm 2.99$ & 0.711 \\
$\mathrm{P}$ plateau $\left(\mathrm{cmH}_{2} \mathrm{O}\right)$ & $18.02 \pm 2.28$ & $17.55 \pm 2.32$ & 0.450 \\
V?E $(\mathrm{l} / \mathrm{min})$ & $7.34 \pm 1.54$ & $8.85 \pm 2.01$ & $0.000^{*}$ \\
Auto-PEEP & $1.34 \pm 0.58$ & $1.28 \pm 0.60$ & 0.634 \\
$\left(\mathrm{cmH} \mathrm{H}_{2} \mathrm{O}\right)$ & & & $0.000^{*}$ \\
Static compliance & $49.40 \pm 14.09$ & $32.42 \pm 11.06$ & \\
(ml/mmHg) & & &
\end{tabular}

Data are expressed as mean \pm SD. $P$ peak, peak pressure; $P$ plateau, plateau pressure; PEEP, positive end expiratory pressure; $\mathrm{RR}$, respiratory rate; V?E, minute ventilation. $P$ value less than 0.05 is considered statistically significant. *means significant.

Table 1 Demographic data and patient characteristics for the studied groups

\begin{tabular}{|c|c|c|c|}
\hline & Simple weaning $(N=60)$ & Nonsimple weaning $(N=42)$ & $P$ value \\
\hline \multicolumn{4}{|l|}{ Demographic data } \\
\hline Age (years) & $59.70 \pm 12.36$ & $61.19 \pm 11.64$ & 0.437 \\
\hline \multicolumn{4}{|l|}{ Sex } \\
\hline Male & $42(70.0)$ & $29(69.0)$ & 0.918 \\
\hline Female & $18(30.0)$ & $13(31.0)$ & \\
\hline BMI $\left(\mathrm{kg} / \mathrm{m}^{2}\right)$ & $28.64 \pm 6.83$ & $27.62 \pm 6.32$ & 0.644 \\
\hline \multicolumn{4}{|l|}{ Smoking } \\
\hline Smoker & $41(68.3)$ & $25(59.5)$ & 0.360 \\
\hline Nonsmoker & $19(31.7)$ & $17(40.5)$ & \\
\hline Smoking index & $29.84 \pm 6.04$ & $28.88 \pm 7.42$ & 0.337 \\
\hline \multicolumn{4}{|l|}{$A B G$ at admission } \\
\hline $\mathrm{pH}$ & $7.24 \pm 0.07$ & $7.23 \pm 0.09$ & 0.746 \\
\hline $\mathrm{PaCO}_{2}(\mathrm{mmHg})$ & $82.55 \pm 19.22$ & $80.79 \pm 22.24$ & 0.930 \\
\hline $\mathrm{PaO}_{2}(\mathrm{mmHg})$ & $52.22 \pm 17.51$ & $53.64 \pm 22.98$ & 0.806 \\
\hline $\mathrm{HCO}_{3}$ & $37.30 \pm 9.75$ & $34.40 \pm 10.26$ & 0.132 \\
\hline $\mathrm{SaO}_{2}(\%)$ & $75.57 \pm 15.62$ & $73.50 \pm 17.63$ & 0.703 \\
\hline $\mathrm{PaO}_{2} / \mathrm{FiO}_{2}$ & $130.54 \pm 43.77$ & $134.11 \pm 57.45$ & 0.806 \\
\hline \multicolumn{4}{|l|}{ Hemodynamic data at admission } \\
\hline Mean blood pressure $(\mathrm{mmHg})$ & $86.60 \pm 22.46$ & $83.26 \pm 21.48$ & 0.528 \\
\hline Respiratory rate (breath/min) & $16.39 \pm 4.48$ & $20.39 \pm 5.38$ & 0.583 \\
\hline Heart rate (beat/min) & $116.42 \pm 18.94$ & $115.19 \pm 17.24$ & 0.528 \\
\hline Temperature $\left({ }^{\circ} \mathrm{C}\right)$ & $37.90 \pm 0.60$ & $38.04 \pm 0.36$ & 0.12 \\
\hline APACHE II score & $19.27 \pm 2.74$ & $22.62 \pm 3.66$ & $0.001^{*}$ \\
\hline
\end{tabular}

Data are presented as mean $\pm \mathrm{SD}$, median (range) or $n(\%)$. ABG, arterial blood gases; APACHE, Acute Physiology And Chronic Health Evaluation. Nonsmoker; those who never smokers. 
Simple weaning group was associated with higher values of RSBI and IWI (Table 3), whereas nonsimple weaning was associated with higher length of mechanical ventilation, duration of ICU stays, extubation failure percentage, tracheostomy need, need for noninvasive mechanical ventilation after weaning and its duration, and mortality outcome (Table 4).

\section{Discussion}

We found that the incidence of simple weaning in our study was 58.8, difficult weaning was 36.3 , and prolonged weaning was 4.9. Similar to our results, one previous study found that the prevalence of the three weaning categories was 54,26 , and $19 \%$, respectively [4]. Moreover, another study reported that the simple weaning incidence was three times more common than the other weaning categories [5].

Regarding the demographic data of the studied patients in the current study, both groups matched regarding age, sex, duration of the disease, BMIs, and smoking status $(P>0.05)$. Similar results were demonstrated by Elgazzar et al. [6] who found that the weaning outcome was not affected by the age, sex, or the state of smoking.
APACHE II score is a major important score used to evaluate the disease severity and the expected mortality. In the current study, there was a major difference between both groups in APACHE II score. This result was in harmony with the results of some previous studies which detected that weaning failure mostly associated with a higher levels of APACHE II score $[7,8]$, but disagree with other studies $[9,10]$.

Regarding the ventilator parameters at the end of the first SBT, we observed that the nonsimple weaning group shows lower levels of the exhaled tidal volume and exhaled minute ventilation, but no significant differences were noted regarding other ventilator parameters. Sellares et al. [11] reported similar results. Exhaled tidal volumes above $5 \mathrm{ml} / \mathrm{kg}$ have been considered as good weaning predictors [12]. However, Monaco et al. [13] found opposite results.

Regarding static compliance measured at the end of the first SBT, we summarized low levels of static compliance in the nonsimple weaning group, and this agrees with one study, which found that there was a significantly decreased respiratory compliance and increased respiratory resistance in the weaning failed group [14], but this result is in contrast with Mabrouk et al. [15].

Table 3 Weaning indices

\begin{tabular}{lccc}
\hline & Simple weaning $(N=60)$ & Nonsimple weaning $(N=42)$ & \\
\hline RSBI (breath/min/l) & $79.47 \pm 24.78$ & $142.02 \pm 50.74$ & $0.035^{\star}$ \\
IWI & $68.69 \pm 39.51$ & $26.45 \pm 17.05$ & $0.000^{*}$ \\
\hline
\end{tabular}

Data are expressed as mean \pm SD. IWI, integrative weaning index; RSBI, rapid shallow breathing index. $P$ value less than 0.05 is considered statistically significant. *means significant.

Table 4 Outcome variables

\begin{tabular}{|c|c|c|c|}
\hline & Simple weaning $(N=60)$ & Nonsimple weaning $(N=42)$ & $P$ value \\
\hline Total duration of mechanical ventilation (days) & $3.66 \pm 1.31$ & $4.44 \pm 2.55$ & $0.042^{*}$ \\
\hline Length of ICU stay (days) & $7.53 \pm 5.26$ & $11.64 \pm 7.79$ & $0.000^{*}$ \\
\hline \multicolumn{4}{|l|}{ Need for NIV } \\
\hline Yes & $19(31.7)$ & $24(57.1)$ & \multirow[t]{2}{*}{$0.010^{*}$} \\
\hline No & $41(68.3)$ & $18(42.9)$ & \\
\hline Duration of NIV (days) & $1.68 \pm 1.19$ & $2.71 \pm 1.59$ & $0.004^{*}$ \\
\hline \multicolumn{4}{|l|}{ Extubation outcome } \\
\hline Success & $52(86.7)$ & $26(64.3)$ & \multirow[t]{2}{*}{$0.003^{*}$} \\
\hline Failure & 8 (13.3) & $16(35.7)$ & \\
\hline \multicolumn{4}{|l|}{ Need for tracheostomy } \\
\hline Yes & $2(3.3)$ & $7(16.7)$ & \multirow[t]{2}{*}{$0.031^{*}$} \\
\hline No & $58(96.7)$ & 35 (83.3) & \\
\hline \multicolumn{4}{|l|}{ Mortality outcome } \\
\hline Died & $3(5.0)$ & $18(42.9)$ & \multirow[t]{2}{*}{$0.000^{*}$} \\
\hline Discharge & $57(95.0)$ & $24(57.1)$ & \\
\hline
\end{tabular}

Data are expressed as mean \pm SD and $n(\%)$. NIV, noninvasive mechanical ventilation. $P$ value less than 0.05 is considered statistically significant. *means significant. 
RSBI was the most commonly studied index to expect the weaning outcome. The value of RSBI in the present study was significantly higher in the nonsimple weaning group $(89.9 \pm 31.7$ vs. $83.7 \pm 21.6)$. These results are concordant with previous studies [15-17], which found that RSBI was significantly less than or equal to 100 in their patients who tolerated the SBT compared with those who failed SBT. However, this result is in contrast with two other studies $[10,18]$. We observed a significant difference in term of IWI between both groups of weaning, Sellares et al. [11] reported similar results.

Ghoneim et al. [19] found that there was a significantly shorter duration of mechanical ventilation in the patients who passed the SBT than those who failed $(P<0.01)$. These results agree with ours finding.

We also summarize a significant difference between both groups regarding the length of ICU stay, and this agrees with Mahmoud and Mohamad [20] who found that the longer duration of ICU stay was one of the most important factors associated with unsuccessful weaning.

In the present work, we observe a significant difference between both groups regarding the need for noninvasive mechanical ventilation after weaning. Sellares et al. [11] documented similar results. ICU mortality in our study was significantly increased in our nonsimple weaning group compared with simple weaning group. In agreement, Boles et al. [2] in their study found that there was a difference in the mortality between the three weaning categories.

\section{Limitations of the study}

Our study is a single-center study with a small sample of selected patients and also has specific clinical characteristics of the study population (patients with COPD). So we need many future studies with a large numbers of patients to emphasizing our results.

\section{Summary and conclusion}

Weaning categorization according to the length and the difficulty of the weaning procedure in mechanically ventilated patients with COPD may be considered as an acceptable predictor of outcome.

\section{Financial support and sponsorship}

Nil.

\section{Conflicts of interest}

There are no conflicts of interest.

\section{References}

1 Díaz MC, Ospina-Tascón GA, Salazar BC. Respiratory muscle dysfunction: a multicausal entity in the critically ill patient undergoing mechanical ventilation. Arch Bronconeumol 2014; 50:73-77.

2 Boles JM, Bion J, Connors A, Herridge M, Marsh B, Melot C, et al. Weaning from mechanical ventilation: statement of the Sixth International Consensus Conference on Intensive Care Medicine. Eur Respir J 2007; 29:1033-1056.

3 Nemer SN, Barbas CS, Caldeira JB, Cárias TC, Santos RG, Almeida LC, et al. Anew integrative weaning index of discontinuation from mechanical ventilation. Crit Care 2009; 13:R152.

4 Tonnelier A, Tonnelier JM, Nowak E, Gut-Gobert C, Prat G, Renault A, et al. Clinical relevance of classification according to weaning difficulty. Respir Care 2011; 56:583-590.

5 Saiphoklang N, Auttajaroon J. Incidence and outcome of weaning from mechanical ventilation in medical wards at Thammasat University Hospital. PLoS one 2018; 13:e0205106.

6 Elgazzar AE, Walaa M, Salah A, Yousif AR. Evaluation of the minute ventilation recovery time as a predictor of weaning in mechanically ventilated COPD patients in respiratory failure. Egypt $J$ Chest Dis Tuber 2013; 62:287-292.

7 Zaytoun T, Mahrous A, Dawood A, Elsammk M, Abd-El-Halim A, Attia A. Chromogranin A ( $\mathrm{ggA})$ as a marker of weaning in mechanically ventilated critically ill septic patients. Egypt J Chest Dis Tuber 2014; 63:955-961.

8 Islam S. APACHE score as a predictive index for weanability from mechanical ventilation. Bangladesh Crit Care 2013; 1:18-22.

9 Sanabria A, Gómez X, Vega V, Domínguez LC, Osorio C. Prediction of prolonged mechanical ventilation for intensive care unit patients: a cohort study. Colomb Med 2013; 44:184-188.

10 Lee CS, Chen NH, Chuang LP, Chang CH, Li LF, Lin SW, et al. Hypercapnic ventilatory response in the weaning of patients with prolonged mechanical ventilation. Can Respir J 2017; 2017: 7381424.

11 Sellares J, Ferrer M, Cano E, et al. Predictors of prolonged weaning and survival during ventilator weaning in a respiratory ICU. Intensive Care Med 2011; 37:775-784.

12 Holliday JE, Hyers TM. The reduction of weaning time from mechanical ventilation using tidal volume and relaxation feedback. Am Rev Respir Dis 1990; 141:1214-1220.

13 Monaco F, Drummond GB, Ramsay P, Servillo G, Walsh TS. Do simple ventilation and gas exchange measurements predict early successful weaning from respiratory support in unselected general intensive care patients? Br J Anaesth 2010; 105:326-333.

14 Metwally A, Hussein K, El-Abdeen AZ, Hamed A, Ez-Eldeen A. The impact of pulmonary functions on outcome of intubated patients with chronic obstructive pulmonary disease. Egypt J Broncho 2015; 9:125-132.

15 Mabrouk AA, Mansour OF, El-Aziz AA, Elhabashy MM, Alasdoudy AA. Evaluation of some predictors for successful weaning from mechanical ventilation. Egypt J Chest Dis Tuber 2015; 64:703-707.

16 Wu YK, Kao KC, Hsu KH, Hsieh MJ, Tsai YH. Predictors of successful weaning from prolonged mechanical ventilation in Taiwan. Respir Med 2009; 103:1189-1195.

17 Pecanha Antonio AC, Basso Gazzana M, Souza Castro P, Knorst M. Fluid balance predicts weaning failure in chronic obstructive pulmonary disease patients. Crit Care 2014; 18:299.

18 Verceles AC, Diaz-Abad M, Geiger-Brown J, Scharf SM. Testing the prognostic value of the rapid shallow breathing index in predicting successful weaning in patients requiring prolonged mechanical ventilation. Heart Lung 2012; 41:546-552.

19 Ghoneim AH, El-Komy HM, Gad DM, Abbas AM. Assessment of weaning failure in chronic obstructive pulmonary disease patients under mechanical ventilation in Zagazig University Hospitals. Egypt $J$ Chest Dis Tuberc 2017; 66:65-74.

20 Mahmoud HM, Mohamad AZ. Predictors of successful weaning from mechanical ventilation. Eur Respir J 2011; 38:5004. 